\title{
The Effect of Aortic Coarctation Surgical Repair on QTe and JTe Dispersion in Severe Aortic Coarctation Newborns: A Short-Term Follow-Up Study
}

\author{
G. NIGRO ${ }^{1}$, V. RUSSO ${ }^{1}$, A. RAGO ${ }^{1}$, A. A. PAPA ${ }^{1}$, N. D. CIOPPA ${ }^{2}$, C. SCARPATI ${ }^{2}$, \\ T. PALLADINO ${ }^{2}$, A. CORCIONE ${ }^{2}$, B. SARUBBI ${ }^{1}$, G. CAIANIELLO ${ }^{3}$, M. G. RUSSO ${ }^{1}$ \\ ${ }^{1}$ Chair of Cardiology, Second University of Naples, Naples, Italy, ${ }^{2}$ Department of Anesthesiology \\ and Reanimation, Monaldi Hospital, Naples, Italy, ${ }^{3}$ Pediatric Cardiac Surgery Unit, Monaldi \\ Hospital, Naples, Italy
}

Received December 6, 2012

Accepted February 28, 2013

On-line November 1, 2013

\section{Summary}

Sudden death is a possible occurrence for newborns younger than 1 year with severe aortic coarctation (COA) before surgical correction. In our previous study, we showed a significant increase of QTC-D and JTC-D in newborns with isolated severe aortic coarctation, electrocardiographic parameters that clinical and experimental studies have suggested could reflect the physiological variability of regional and ventricular repolarization and could provide a substrate for life-threatening ventricular arrhythmias. The aim of the current study was to evaluate the effect of surgical repair of CoA on QTc-d, JTc-d in severe aortic coarctation newborns with no associated congenital cardiac malformations. The study included 30 newborns (18M; $70 \pm 12 \mathrm{~h}$ old) affected by severe congenital aortic coarctation, without associated cardiac malformations. All newborns underwent to classic extended end-to-end repair. Echocardiographic and electrocardiographic measurements were performed in each patient $24 \mathrm{~h}$ before and $24 \mathrm{~h}$ after the interventional procedure and at the end of the follow-up period, 1 month after the surgical correction. All patients at baseline, $24 \mathrm{~h}$ and one month after CoA surgical repair did not significantly differ in terms of heart rate, weight, height, and echocardiographic parameters. There were no statistically significant differences in QTC-D (111.7 \pm 47.4 vs $111.9 \pm 63.8 \mathrm{~ms}$ vs $108.5 \pm 55.4 \mathrm{~ms} ; P=0.4)$ and JTc-D $(98.1 \pm 41.3$ vs $111.4 \pm 47.5$ vs $105.1 \pm 33.4 \mathrm{~ms} ; P=0.3$ ) before, $24 \mathrm{~h}$ and 1 month after CoA surgical correction. In conclusions, our study did not show a statistically significant decrease in QTC-D and JTC$D$, suggesting the hypothesis that the acute left ventricular afterload reduction, related to successful CoA surgical correction,
\end{abstract}

may not reduce the ventricular electrical instability in the shortterm follow-up.

\section{Key words}

QT dispersion • JT dispersion • Aortic coarctation • Repolarization

\section{Corresponding author}

Andrea Antonio Papa, Via Leonardo Bianchi, 80100 Naples, Italy. E-mail: andreaantoniopapa@libero.it

\section{Introduction}

Aortic coarctation $(\mathrm{CoA})$ is a relatively common defect that accounts for 5-8\% of all congenital heart defects and it may be defined as a constricted aortic segment that comprises localized medial thickening, with some infolding of the medial and superimposed neointimal tissue (Rao 1995). CoA imposes significant afterload on the left ventricle, which results in early increased wall stress and late compensatory ventricular hypertrophy. Sudden cardiac death can occur in infants under the age of 1 year with undiagnosed aortic coarctation (Råsten-Almqvist and Rajs 2004). Clinical and experimental studies have suggested that QTc dispersion (QTC-D) and JTc dispersion (JTc-D) could reflect the physiological variability of regional and ventricular repolarization (Zabel et al. 1995, Nigro et al. 2010, 2012, Russo et al. 2007, 2012) and could provide a substrate for life-threatening ventricular arrhythmias, and 
subsequent sudden death, in hypertrophic cardiomyopathy (Buja et al. 1993), chronic heart failure (Barr et al. 1994, Nigro et al. 2008, Santangelo et al. 2006), myocardial ischemia (Higham et al. 1995, Paventi et al. 1999) and beta thalassemia major (Russo et al. 2011). In our previous study, we showed a significant increase of QTc-D and JTc-D in newborns with isolated severe aortic coarctation (Nigro et al. 2011), but little is still known about the influence of surgical correction on the heterogeneity of ventricular repolarization. The aim of our study was to evaluate the effect of surgical CoA repair on electrocardiographic parameters of ventricular repolarization heterogeneity (QTc-d, JTc-d) in severe aortic coarctation newborns.

\section{Materials and Methods}

\section{Patients selection}

The study included 30 newborns (18M; 70 $12 \mathrm{~h}$ old) affected by severe congenital aortic coarctation, without associated cardiac malformations. Newborns with diabetes, electrolyte imbalance, cardiomegaly, connective tissue disorders, other cardiac congenite malformations associated, left bundle branch block or atrioventricular conduction abnormalities on electrocardiogram (ECG), hepatic, renal or thyroid diseases were excluded from the study. All patients were in sinus rhythm, and none of them was taking medications known to affect electrocardiographic intervals. All patients were requiring medical therapy with prostaglandin E1 to keep the ductus arteriosus open, which was given at a dose of $0.05-0.1 \mu \mathrm{g} / \mathrm{kg} / \mathrm{min}$ continuous intravenous infusion. Two of them were taking prostaglandin E1 in combination with dopamine at low dose $(6-8 \mu \mathrm{g} / \mathrm{kg} / \mathrm{min})$ to increase the contractility of cardiac muscle and to avoid congestive heart failure. The study was performed in accordance with the rules of the Ethical Committee of Second University of Naples. All parents gave their written informed consent to participate in the study.

\section{Surgical technique}

All newborns underwent to classic extended end-to-end repair (Wright et al. 2005). Standard monitoring included a right radial arterial catheter and a blood pressure cuff on the left or right leg. Positioning the patient in the lateral decubitus position followed inhalation induction of general endotracheal anesthesia. All neonates undergone surgical treatment by left lateral- posterior thoracotomy, the pleural cavity was entered through the $3 \mathrm{rd}$ or 4 th left intercostal space with selective intubation of the lungs. The mediastinal pleura was opened after identifying the recurrent laryngeal nerve and the coarcted segment of the aorta was exposed. The ductus arteriosus was either clipped or sutured and divided. Mobilization of the subclavian artery, the distal aortic arch, and the descending aorta was accomplished. In all patients intravenous administration of heparin was performed. In all patients the correction was performed using synthetic tubes. It was performed the interposition of the tube replacing the coarctate aorta segment by endto-end anastomosis with the proximal and distal stumps of the aorta; performing the proximal anastomosis with the subclavian artery and the distal anastomosis with the descending aorta, after the aortic coarctation.

\section{Study protocol}

Familiar anamnesis, physical examination, anthropometric evaluation, 12-lead surface ECG, 2D Color Doppler Echocardiogram and ECG Holter $24 \mathrm{~h}$ monitoring were performed in the study population. Electrocardiographic measurements, recorded at a speed of $50 \mathrm{~mm} / \mathrm{s}$, were performed in all patients of the study population $24 \mathrm{~h}$ before and $24 \mathrm{~h}$ after interventional procedure and at the end of the follow-up period, 1 month after the surgical correction.

\section{Electrocardiographic measurements}

All subjects underwent a routine standard twelve-lead body surface electrocardiograms (ECGs), recorded at a paper speed of $50 \mathrm{~mm} / \mathrm{s}$ and gain of $10 \mathrm{~mm} / \mathrm{mV}$, in the recumbent position and were breathing freely during the ECG recording. To avoid diurnal variations, we generally analyzed the ECG recordings of the subjects at the same time (10.00-11.00 A.M.). The analysis was performed by one experienced cardiologist who was blinded to the clinical presentation of the infants. Electrocardiograms were transferred to a personal computer by an optical scanner and then magnified 400 times by Adobe Photoshop software (Adobe Systems Incorporated, San Jose, CA). QRS duration, QT interval and JT interval were manually performed with the use of computer software (configurable measurement system). The variability of the measurements was $6 \pm 0.28 \mathrm{~ms}$, not statistically significant. In each electrocardiogram lead, the analysis included three consecutive heart cycles, wherever possible. Leads were excluded from analysis when the end of the T-wave was not clearly 
Table 1. Clinical and echocardiographic characteristics of the study population.

\begin{tabular}{|c|c|c|c|}
\hline & Baseline & $24 \mathrm{~h}$ after correction & 1 month after correction \\
\hline Patients (n) & 30 & 30 & 30 \\
\hline Gestational age (weeks) & $38 \pm 2$ & $38 \pm 2$ & $38 \pm 2$ \\
\hline Age (hours) & $70 \pm 12$ & $71 \pm 12$ & $100 \pm 12$ \\
\hline Sex (male/female) & $18 / 12$ & $18 / 12$ & $18 / 12$ \\
\hline Weight (kg) & $3.256 \pm 0.37$ & $3.260 \pm 0.31$ & $4.750 \pm 0.65$ \\
\hline Height $(\mathrm{cm})$ & $51.7 \pm 1.50$ & $51.7 \pm 1.50$ & $58.15 \pm 2.47$ \\
\hline Head circumference $(\mathrm{cm})$ & $37.2 \pm 1.30$ & $37.2 \pm 1.30$ & $39.20 \pm 1.45$ \\
\hline$H R(b p m)$ & $129 \pm 7.47$ & $125 \pm 7.59$ & $116 \pm 6.15$ \\
\hline$\Delta P(m m H g)$ & $44.1 \pm 13.6$ & $12.7 \pm 7.9$ & $13.5 \pm 6.2$ \\
\hline LVESD (mm) & $14.85 \pm 1.7$ & $14.02 \pm 0.85$ & $15.01 \pm 1.25$ \\
\hline$L V E D D(\mathrm{~mm})$ & $20.1 \pm 1.4$ & $20.5 \pm 1.9$ & $22.1 \pm 1.4$ \\
\hline $\operatorname{IVSTd}(\mathrm{mm})$ & $4.5 \pm 0.8$ & $4.6 \pm 0.5$ & $5.0 \pm 0.2$ \\
\hline LVPWTd $(\mathrm{mm})$ & $3.9 \pm 0.3$ & $3.9 \pm 0.5$ & $4.07 \pm 0.06$ \\
\hline $\operatorname{LVM}(g)$ & $12.5 \pm 2.59$ & $12.7 \pm 2.87$ & $15.26 \pm 2.65$ \\
\hline TAPSE (mm) & $20 \pm 0.5$ & $21 \pm 0.4$ & $21 \pm 0.2$ \\
\hline RVFSA (\%) & $41.5 \pm 1.3$ & $42 \pm 1.1$ & $42.1 \pm 1.2$ \\
\hline
\end{tabular}

$(H R)$ heart rate, $(\triangle P)$ peak gradient across the coarctation site, (LVESD) left ventricular end systolic diameter,(LVEDD) left ventricular end diastolic diameter, (IVSTd) interventricular septum thickness at end diastole, (LVPWTd) left ventricular posterior wall thickness at end diastole, (LVM) left ventricular mass, (TAPSE) tricuspid annular plane systolic excursion, (RVFSA) right ventricular fractional shortening area

distinguishable or the signal quality was too poor for analysis. The QRS interval was measured from the start of the Q wave or, in the absence of the $\mathrm{Q}$ wave, from the start of $\mathrm{R}$ wave to the end of $\mathrm{S}$, that is to its return to the isoelectric line. The QT interval was measured from the initial deflection of the QRS complex to the end of the T wave, that is to the point where the $\mathrm{T}$ wave returned to the isoelectric line (Lepeschkin and Surawicz 1952). When U wave was present, the QT was measured to the nadir of the curve between the $\mathrm{T}$ and $\mathrm{U}$ waves. If the end of the $\mathrm{T}$ wave could not be reliably determined or if the $\mathrm{T}$ waves were isoelectric or of very low amplitude, measurements were not done and these leads were excluded from analysis. The JT interval was derived by subtracting the QRS duration from the QT interval (Kremastinos et al. 2001). QTd was the difference between the maximal and the minimal QT value in all leads (Hahalis et al. 2001). The difference between the maximal and the minimal JT value in all leads was defined as JTd. All measurements were corrected for heart rate using Bazett's formula $(\mathrm{QTc}=\mathrm{QT} / \sqrt{\mathrm{R} R}$; $\mathrm{JTc}=\mathrm{JT} / \sqrt{\mathrm{RR}})($ Ahnve 1985, Bazett 1920).

\section{Echocardiographic evaluation}

Images were gathered with a standard ultrasound machine with a $7 \mathrm{MHz}$ phased-array probe. All the echocardiographic studies were digitally stored, and all the measurements were performed off-line by two independent observers who were blinded to the clinical status of the subjects. Selected parameters were measured according to the American Society of Echocardiography recommendations (Picard et al. 2011) in M-mode from parasternal long-axis view: left ventricular end diastolic diameter (LVEDD), left ventricular end systolic diameter (LVESD), interventricular septum thickness (IVST), left ventricular posterior wall thickness (LVPT). LVM was calculated by using Devereux's formula, and was indexed for body surface area and height (Devereux et al. 1986). Using the suprasternal approach, instantaneous Doppler peak pressure gradient (PPG), across the coarctation site, was measured by continuous wave Doppler study using a simplified Bernoulli equation. Average values of these indexes, obtained from 5 consecutive cardiac cycles, were used for the analysis. A cut off value of $30 \mathrm{~mm} \mathrm{Hg}$ was used to include the newborns in the study population.

\section{Statistical analysis}

Statistical analysis was performed using Student's t-test for paired data and one-way analysis of variance (ANOVA) coupled with Newman-Keuls post- 
hoc test for multiple comparisons. Data are presented as mean \pm SD. Differences were considered to be significant at a P-value $<0.05$. Analyses were performed using the statistical package SPSS 11.0 software for Windows (Chicago, Illinois, USA).

\section{Results}

\section{Clinical and echocardiographic parameters}

Table 1 summarizes the clinical and echocardiographic characteristics of the study population at baseline, $24 \mathrm{~h}$ and one month after CoA surgical repair. Compared with the baseline values, the patients showed a significant decrease average peak gradient across the coarctation site after CoA repair $(44.1 \pm 13.6$ vs $12.7 \pm$ $5.3 \mathrm{~mm} \mathrm{Hg} ; P=0.004)$, also confirmed at the end of our follow-up period $(12.7 \pm 5.3$ vs $13.5 \pm 6.2 \mathrm{~mm} \mathrm{Hg} ; P=0.2)$. No statistically significant differences were found in left ventricular end-diastolic diameter (LVEDD, 20.1 \pm 1.4 vs $20.5 \pm 1.9$ vs $22.1 \pm 1.4 \mathrm{~mm} ; P=0.3)$, left ventricular endsystolic diameter (LVESD, $14.85 \pm 1.7$ vs $14.02 \pm 0.85$ vs $15.01 \pm 1.25 \mathrm{~mm} ; P=0.2)$, interventricular septum thickness at end diastole (IVSTd, $4.5 \pm 0.8$ vs $4.6 \pm 0.5$ vs $5.0 \pm 0.2 \mathrm{~mm}$; $P=0.3$ ), left ventricular posterior wall thickness at end diastole (LVPWTd, $3.9 \pm 0.3$ vs $3.9 \pm 0.5$ vs $4.07 \pm 0.06 \mathrm{~mm}$; $P=0.3$ ) or left ventricular mass (LVM, $12.5 \pm 2.59$ vs $12.7 \pm 2.87$ vs $15.26 \pm 2.65 \mathrm{~g} ; P=0.07)$, tricuspid annular plane systolic excursion (TAPSE, $20 \pm 0.5$ vs $21 \pm 0.4$ vs $21 \pm 0.2 \mathrm{~mm}$ ) or right ventricular fractional shortening area (RVFSA, $41.5 \pm 1.3 \%$ vs $42 \pm 1.1 \%$ vs $42.1 \pm 1 \%$ ) at baseline, $24 \mathrm{~h}$ and one month after CoA repair.

Heart rate, QTc, JTc, QTc-d and JTc-d

Electrocardiographic values before and after CoA surgical correction are shown in Table 2. All patients were in sinus rhythm before and after the surgical correction. There were no statistically significant differences in QTc-D (111.7 \pm 47.4 vs $111.9 \pm 63.8 \mathrm{~ms} v s$ $108.5 \pm 55.4 \mathrm{~ms} ; \quad P=0.4)$ and JTc-D $(98.1 \pm 41.3 \quad v s$ $111.4 \pm 47.5$ vs $105.1 \pm 33.4 \mathrm{~ms} ; P=0.3)$ before, $24 \mathrm{~h}$ and 1 month after CoA surgical correction. Absolute value of intraobserver variability of QTc and JTc dispersion measurement was $7 \pm 3 \mathrm{~ms}$ and $6 \pm 4 \mathrm{~ms}$, respectively.

\section{Discussion}

\section{Background}

QTc-d and JTc-d are electrocardiographic markers of ventricular repolarization heterogeneity and reflects the regional differences in cellular action potential duration and in ventricular recovery time. The prolongation of QTc-d and JTc-d increases the risk of development of malignant ventricular arrhythmias, probably via two mechanisms. First, it facilitates transmural early afterdepolarization propagation; second, it could cause intramural functional conduction blocks that predispose to re-entrant polymorphic ventricular tachyarrhythmias. Several studies have suggested that JTc-d is clinically useful in assessing arrhythmia risk (Kuo et al. 1983, Vassallo et al. 1988) because it is a parameter less dependent on ventricular depolarization and reflect the ventricular repolarization heterogeneities better than QTc-d in patients with intra-ventricular conduction abnormalities (Merx et al. 1977, Kuo et al. 1985). According to our previous study, newborns with isolate severe aortic coarctation showed increased QTc-d and JTc-d compared to age and sex matched healthy control group (Nigro et al. 2011). Our results suggested the hypothesis that the left ventricular afterload related to severe aortic coarctation, in absence of ventricular hypertrophy, may increase the

Table 2. Electrocardiographic measurements before and $24 \mathrm{~h}$ after surgical repair and the end of follow-up period.

\begin{tabular}{|c|c|c|c|}
\hline & Before correction & $24 \mathrm{~h}$ after correction & 1 month after correction \\
\hline$R-R$ interval (ms) & $475 \pm 32$ & $486 \pm 51$ & $492 \pm 60$ \\
\hline$Q R S \max (m s)$ & $129.3 \pm 81.7$ & $107 \pm 26.2$ & $114 \pm 35.6$ \\
\hline$Q R S \min (m s)$ & $71.9 \pm 5.1$ & $66.9 \pm 13.2$ & $68.5 \pm 16.2$ \\
\hline QTc $\max (\mathrm{ms})$ & $431.8 \pm 25.6$ & $468.8 \pm 76.9$ & $459.5 \pm 85.9$ \\
\hline$Q T c \min (m s)$ & $278.5 \pm 107.1$ & $356.9 \pm 26.9$ & $358 \pm 22.7$ \\
\hline$Q T c-D(m s)$ & $111.7 \pm 47.4$ & $111.9 \pm 63.8$ & $108.5 \pm 55.4$ \\
\hline JTc max (ms) & $356.9 \pm 24.8$ & $346.2 \pm 50.8$ & $351.1 \pm 48.6$ \\
\hline$J T c \min (m s)$ & $201.3 \pm 64.2$ & $234.7 \pm 17.2$ & $236.5 \pm 26.3$ \\
\hline$J T c-D(m s)$ & $98.1 \pm 41.3$ & $111.4 \pm 47.5$ & $105.1 \pm 33.4$ \\
\hline
\end{tabular}


ventricular repolarization heterogeneity and produce the electrophysiological substrate for ventricular malignant tachyarrhythmias and sudden death. Sarubbi et al. (2004) showed a decrease of dispersion of ventricular repolarization time electrocardiographic indexes in patients affected by severe aortic coarctation who underwent successful percutaneous balloon valvuloplasty; they postulated that reduction of left ventricular size and end diastolic pressure in patients with left ventricular dysfunction may be of benefit in preventing ventricular arrhythmias. However, to our knowledge, in literature, there are any data about the effects of surgical CoA repair on parameters of ventricular repolarization heterogeneity in severe aortic coarctation newborns.

\section{Main findings}

This is the first study that evaluated the effects of surgical CoA repair on the heterogeneity of ventricular repolarization, by examining QTc-D and JTc-D, in a population of newborns affected by isolated severe coarctation of the aorta. Studying the effect of surgical CoA repair in severe aortic coarctation newborns, without ventricular hypertrophy and without other associated congenital cardiac malformations, might have offered the unique clinical opportunity to exclude the influence of possible comorbidities on the evaluation of heterogeneity of ventricular repolarization. 24 hours after successful surgical CoA correction, despite an acute reduction in peak-to-peak systolic gradient across the coarctation site, we did not observe a QTc-d and JTc-d decrease. The lack of decrease in the heterogeneity of ventricular repolarization parameters, in the acute phase after surgical intervention, suggests the hypothesis that the left ventricular afterload reduction, related to successful CoA surgical correction, may not reduce the ventricular electrical instability in the acute phase and even after 1 month. These results can be explained by the electrical instability leading to surgical repair (Punn et al. 2011), or because the acute reduction of the myocardial wall stretch, leading to the regression of pressure overload, not lead to reverse electrical remodeling, at least not in the acute and subacute phase.

\section{Limitations}

The small number of patients included is certainly a limitation, and a more extensive study is needed to confirm these data. QT interval and JT interval were made on 12-lead ECGs, with the use of computer software and digitizer by an experienced cardiologist observer. However, there remains an absence of indisputable, generally accepted criteria, for the definition of the end of $T$ interval implying some degree of possible error in the measurements. The 12-lead surface ECG, compared with body surface mapping or vector cardiography, gives an incomplete picture of cardiac electric activity, so QTd could not be a true manifestation of local heterogeneity of repolarization. We did not consider the possible direct effect that different doses of dopamine may have on ventricular repolarization. However, only two patients in the study population were taking dopamine at low doses, and no previous studies in the literature had established the effects of dopamine on QT dispersion. We assessed right ventricular systolic function through TAPSE and RVFSA echocardiographic measurement; we did not measure other systolic and diastolic right ventricular function indexes such as myocardial performance index (MPI) or other parameters derivable from tissue Doppler imaging (TDI) such as systolic ejection velocity $(\mathrm{Sm})$ or early diastolic velocity (Em) and diastolic velocity consequent to atrial contraction (Am). However, these last cited parameters are little used in the echocardiographic evaluation of newborns. The short period of follow-up is certainly a limit, and further studies are needed to evaluate a possible regression of the electrical instability after a greater follow-up period.

\section{Conclusion}

Our study did not show a statistically significant decrease in QTc-D and JTc-D, electrocardiographic parameters considered to reflect the heterogeneity of the ventricular repolarization, $24 \mathrm{~h}$ after surgical CoA repair and at one month follow-up. Our results suggested the hypothesis that the acute left ventricular afterload reduction, related to successful CoA surgical correction, may not reduce the ventricular electrical instability in the short-term follow-up.

\section{Conflict of Interest}

There is no conflict of interest. 


\section{References}

AHNVE S: Correction of the QT interval for heart rate: review of different formulas and the use of Bazett's formula in myocardial infarction. Am Heart J 109: 568-574, 1985.

BAZETT HC: An analysis of the time-relations of electrocardiograms. Heart 7: 353-370, 1920.

BARR CS, NASS A, FREEMAN M, LANG CC, STRUTHERS AD: QT dispersion and sudden unexpected death in chronic heart failure. Lancet 343: 327-329, 1994.

BUJA G, MIORELLI M, TURRINI P, MELACINI P, NAVA A: Comparison of QT dispersion in hypertrophic cardiomyopathy between patients with and without ventricular arrhythmias and sudden death. Am J Cardiol 72: 973-976, 1993.

DEVEREUX RB, ALONSO DR, LUTAS EM, GOTTLIEB GJ, CAMPO E, SACHS I, REICHEK N: Echocardiographic assessment of left ventricular hypertrophy: comparison to necropsy findings. Am J Cardiol 57: 450-458, 1986.

HAHALIS G, MANOLIS AS, GERASIMIDOU I, ALEXOPOULOS D, SITAFIDIS G, KOURAKLI A, KÖRFER R, KOERNER MM, VAGENAKIS AG, ZOUMBOS NC: Right ventricular diastolic function in beta-thalassemia major: Echocardiographic and clinical correlates. Am Heart J 141: 428-434, 2001.

HIGHAM PD, FURNISS SS, CAMPBELL RW: QT dispersion and components of the QT interval in ischaemia and infarction. Br Heart J 73: 32-36, 1995.

KREMASTINOS DT, TSETSOS GA, TSIAPRAS DP, KARAVOLIAS GK, LADIS VA, KATTAMIS CA: Heart failure in beta thalassemia: a 5-year follow-up study. Am J Med 111: 349-354, 2001.

KUO CS, MUNAKATA K, REDDY CP, SURAWICZ B: Characteristics and possible mechanism of ventricular arrhythmia dependent on the dispersion of action potential durations. Circulation 67: 1356-1367, 1983.

KUO CS, REDDY CP, MUNAKATA K, SURAWICZ B: Mechanism of ventricular arrhythmias caused by increased dispersion of repolarization. Eur Heart $J 6$ (Suppl D): 63-70, 1985.

LEPESCHKIN E, SURAWICZ B: The measurements of the QT interval of the electrocardiogram. Circulation 6: 378388, 1952.

MERX W, YOON MS, HAN J: The role of local disparity in conduction and recovery time on ventricular vulnerability to fibrillation. Am Heart J 94: 603-610, 1977.

NIGRO G, RUSSO V, VERGARA P, D’ANDREA A, DI GREGORIO G, POLITANO L, NIGRO G, CALABRÒ R: Optimal site for atrial lead implantation in myotonic dystrophy patients: the role of Bachmann's Bundle stimulation. Pacing Clin Electrophysiol 31: 1463-1466, 2008.

Nigro G, RUSSO V, Di SALVO G, De CRESCENZO I, RAGO A, PERRONE L, GOLINO P, RUSSO MG, CALABRÒ R: Increased heterogenity of ventricular repolarization in obese nonhypertensive children. Pacing Clin Electrophysiol 33: 1533-1539, 2010.

NIGRO G, RUSSO V, RAGO A, PAPA AA, CIOPPA ND, Di MEO F, CORCIONE A, CAIANIELLO G, RUSSO MG, CALABRÒ R: Heterogeneity of ventricular repolarization in newborns with severe aortic coarctation. Pediatr Cardiol 33: 302-306, 2011.

NIGRO G, RUSSO V, RAGO A, PAPA AA, CARBONE N, MARCHEL M, PALLADINO A, HAUSMANOWAPETRUSEWICZ I, RUSSO MG, POLITANO L: Regional and transmural dispersion of repolarisation in patients with Emery-Dreifuss muscular dystrophy. Kardiol Pol 70: 1154-1159, 2012.

PAVENTI S, BEVILACQUA U, PARAFATI MA, DI LUZIO E, ROSSI F, PELLICCIONI PR: QT dispersion and early arrhythmic risk during acute myocardial infarction. Angiology 50: 209-215, 1999.

PICARD MH, ADAMS D, BIERIG SM, DENT JM, DOUGLAS PS, GILLAM LD, KELLER AM, MALENKA DJ, MASOUDI FA, MCCULLOCH M, PELLIKKA PA, PETERS PJ, STAINBACK RF, STRACHAN GM, ZOGHBI WA: American Society of Echocardiography recommendations for quality echocardiography laboratory operations. $J$ Am Soc Echocardiogr 24: 1-10, 2011.

PUNN R, LAMBERTI JJ, BALISE RR, SESLAR SP: QTc prolongation in children following congenital cardiac disease surgery. Cardiol Young 21: 400-410, 2011.

RAO PS: Should balloon angioplasty be used instead of surgery for native aortic coarctation? Br Heart J 74: 578-579, 1995. 
RÅSTEN-ALMQVIST P, RAJS J: Cardiovascular malformations and sudden death in infancy. Am J Forensic Med Pathol 25: 134-140, 2004.

RUSSO V, AMMENDOLA E, DE CRESCENZO I, RICCIARDI D, CAPUANO P, TOPATINO A, DOCIMO L, SANTANGELO L, CALABRÒ R: Effect of weight loss following bariatric surgery on myocardial dispersion of repolarization in morbidly obese patients. Obes Surg 17: 857-865, 2007.

RUSSO V, RAGO A, PANNONE B, PAPA AA, DI MEO F, MAYER MC, SPASIANO A, RUSSO MG, GOLINO P, CALABRÒ R, NIGRO G: Dispersion of repolarization and beta thalassemia major: the prognostic role of QT and JT dispersion for identifyng the high risk patients for sudden death. Eur J Haematol 86: 324-331, 2011.

RUSSO V, RAGO A, POLITANO L, PAPA AA, Di MEO F, RUSSO MG, GOLINO P, CALABRÒ R, NIGRO G: Increased dispersion of ventricular repolarization in Emery Dreifuss muscular dystrophy patients. Med Sci Monit 18: CR643-CR647, 2012.

SANTANGELO L, AMMENDOLA E, RUSSO V, CAVALLARO C, VECCHIONE F, CAROFALO S, D’ONOFRIO A, CALABRÒ R: Influence of biventricular pacing on myocardial dispersion of repolarization in dilated cardiomyopathy patients. Europace 8: 502-505, 2006.

SARUBBI B, CALVANESE R, CAPPELLI BIGAZZI M, SANTORO G, GIOVANNA RUSSO M, CALABRÒ R: Electrophysiological changes following balloon valvuloplasty and angioplasty for aortic stenosis and coartaction of aorta: clinical evidence for mechano-electrical feedback in humans. Int J Cardiol 93: 7-11, 2004.

VASSALLO JA, CASSIDY DM, KINDWALL KE, MARCHLINSKI FE, JOSEPHSON ME: Nonuniform recovery of excitability in the left ventricle. Circulation 78: 1365-1372, 1988.

WRIGHT GE, NOWAK CA, GOLDBERG CS, OHYE RG, BOVE EL, ROCCHINI AP: Extended resection and endto-end anastomosis for aortic coarctation in infants: results of a tailored surgical approach. Ann Thorac Surg 80: 1453-1459, 2005.

ZABEL M, PORTNOY S, FRANZ MR: Electrocardiographic indexes of dispersion of ventricular repolarization: an isolated heart validation study. J Am Coll Cardiol 25: 746-752, 1995. 